The Effect of Solution Annealing on the Microstructural Behavior of Alloy 22 Welds

B. S. El-Dasher, T. S. Edgecumbe, S. G. Torres

May 11, 2005

Metallurgical and Materials Transactions A 
This document was prepared as an account of work sponsored by an agency of the United States Government. Neither the United States Government nor the University of California nor any of their employees, makes any warranty, express or implied, or assumes any legal liability or responsibility for the accuracy, completeness, or usefulness of any information, apparatus, product, or process disclosed, or represents that its use would not infringe privately owned rights. Reference herein to any specific commercial product, process, or service by trade name, trademark, manufacturer, or otherwise, does not necessarily constitute or imply its endorsement, recommendation, or favoring by the United States Government or the University of California. The views and opinions of authors expressed herein do not necessarily state or reflect those of the United States Government or the University of California, and shall not be used for advertising or product endorsement purposes. 


\title{
The Effect of Solution Annealing on the Microstructural Behavior of Alloy 22 Welds
}

\author{
Bassem S. El-Dasher ${ }^{1}$, Tammy S. Edgecumbe ${ }^{2}$, and Sharon G. Torres ${ }^{1}$ \\ ${ }^{1}$ Lawrence Livermore National Laboratory, L-631, P.O.Box 808, Livermore, CA 94550, USA \\ ${ }^{2}$ Lawrence Livermore National Laboratory, L-353, P.O.Box 808, Livermore, CA 94550, USA
}

Multi-pass gas tungsten arc welds of Alloy 22 were subjected to solution annealing durations of 20 minutes, 24 hours, 72 hours and 1 week at temperatures of $1075,1121,1200$, and $1300^{\circ} \mathrm{C}$. The specimens were studied in cross section by secondary electron microscopy to determine the effect of solution annealing on tetrahedrally close packed (TCP) precipitate stability. Electron backscatter diffraction mapping was also performed on all of the specimens to determine the recrystallization behavior of the welds. It was found that complete TCP precipitate dissolution occurs after solution annealing at $1075^{\circ} \mathrm{C}$ and $1121^{\circ} \mathrm{C}$ for 24 hours, and at $1200^{\circ} \mathrm{C}$ and $1300^{\circ} \mathrm{C}$ for durations of 20 minutes. Regions of most rapid recrystallization were correlated to the regions of lowest solute content and highest residual tensile stresses. Texture analysis indicated that while the columnar dendrites originally present in the weld grew with a $<001>$ orientation in the transverse direction (opposite the heat flow direction), the recrystallized grains adopt a $<101>$ orientation in the transverse direction when recrystallization and TCP phase dissolution occur simultaneously.

\section{INTRODUCTION}

Alloy 22 (UNS N06022) is a nickel-based alloy containing approximately 22\% chromium, 13\% molybdenum, $3 \%$ iron, and $3 \%$ tungsten $^{[1]}$. It is of current technological importance due to its selection as the candidate material for the outer barrier of the nuclear waste containers for the proposed repository site at Yucca Mountain, Nevada ${ }^{[2,3]}$. Its selection is primarily due to its excellent resistance to pitting and crevice corrosion, as well as to stress corrosion cracking ${ }^{[4-9]}$.

Although the phase stability of this and similar alloys has primarily been studied in the mill-annealed condition

${ }^{[10,11]}$, few studies have been performed on its welding metallurgy ${ }^{[12-14]}$. From this previous work, it is known that Alloy 22 welds form potentially detrimental intermetallic tetrahedrally close packed (TCP) phases upon solidification. Their effect on material properties was highlighted in a study of Alloy 22 specimens artificially aged 
at high temperatures, which correlated a decrease in corrosion performance and mechanical properties to TCP phase formation ${ }^{[15]}$. The implications of this are clear when one considers that multiple welds are required for the construction of the waste package outer barrier.

Traditionally for Alloy 22, solution annealing has been employed to eliminate the TCP phases from solidified microstructures, and is performed at the manufacturer recommended temperature of $1121^{\circ} \mathrm{C}\left(2050^{\circ} \mathrm{F}\right)^{[16]}$. A study on the effect of solution annealing on TCP phase stability was conducted by Pan $e t . a l^{[17]}$. Specimens were treated at temperatures ranging from $1125^{\circ} \mathrm{C}$ to $1300^{\circ} \mathrm{C}$. It was determined that an annealing treatment of up to 1 hour at $1125^{\circ} \mathrm{C}$ did not dissolve the TCP phases, while treatments at temperatures between $1200^{\circ} \mathrm{C}$ and $1300^{\circ} \mathrm{C}$ for 15 minutes also did not dissolve the TCP phases but led to microstructural homogenization. Volume fraction measurements also indicated that the TCP phases grew during the solution annealing.

In contrast, work comparing a specimen solution annealed at $1121^{\circ} \mathrm{C}$ for 20 minutes to an as-welded specimen was recently performed, and showed a relative TCP phase volume fraction decrease of approximately $5 \%{ }^{[18]}$ after solution annealing. Also observed was a trend in the TCP phase size distribution such that the number of coarser TCP phases increased at the expense of the smaller TCP phases (as compared to the as-welded condition), and that the regions with recrystallization are primarily those with lower TCP phase content. The differences between both studies was that in the former the TCP phases were measured in select areas, while in the latter the TCP phase volume was measured by imaging the entire weld cross-section. This then indicates that the inhomogeneities of the weld can play a large part in the resultant observations. To properly ascertain the effect of solution annealing on the behavior of the microstructure, it is necessary to study the effects of treatment for durations longer than 1 hour.

In this paper we examine the behavior of TCP phase stability and microstructural evolution of Alloy 22 welds solution annealed as a function of solution annealing temperature $\left(1075^{\circ} \mathrm{C}\right.$ to $\left.1300^{\circ} \mathrm{C}\right)$ and duration $(20$ minutes to 1 week).

\section{EXPERIMENTAL PROCEDURE}

Specimens used in this study were cut from a 30” $(762 \mathrm{~mm})$ long, 1.5 ” $(38.1 \mathrm{~mm})$ thick welded plates. The plates were produced by double-U multi-pass gas-tungsten-arc welds fabricated using 1.5” mill annealed Alloy 22 plates and matching Alloy 22 filler rod (ERNiCrMo-10) ${ }^{[19]}$. All specimens were cut from the same plate to minimize compositional variability between the specimens. Cutting was performed using an abrasive water jet to produce seventeen 0.5 ” $(12.7 \mathrm{~mm})$ wide cross-sectional specimens. This method was employed specifically to minimize heat 
input during the cutting process thereby minimizing any unwanted side effects on the microstructure. The chemical compositions of the mill annealed plate and the weld filler rod are given in Table I.

Sixteen of the seventeen specimens were annealed in air furnaces, such that four sets of four specimens were annealed at $1075^{\circ} \mathrm{C}, 1121^{\circ} \mathrm{C}, 1200^{\circ} \mathrm{C}$, and $1300^{\circ} \mathrm{C}$. One specimen of each set was annealed at the corresponding temperature for 20 minutes, 24 hours, 72 hours, and 168 hours (1 week). All specimens were water quenched upon the completion of their respective solution annealing treatment.

Figure 1 schematically illustrates the weld cross-section used in the study. This cross section was utilized since it permitted the observation of weld pass effects on the microstructure. The specimens were metallographically prepared by grinding using progressively finer grit down to 1200 grit, and subsequently polishing to $0.02 \mu \mathrm{m}$ colloidal silica. No etching was performed. The boxed region in Figure 1 shows the area studied in this work. The study was limited to this area due to the symmetry of the weld about the weld center, and hence the redundancy of studying the whole weld.

Two methods were applied to characterize the weld microstructure: backscatter electron imaging in a scanning electron microscope (SEM) to characterize the TCP phases and electron backscatter diffraction (EBSD) to determine the weld crystallography. The experimental details of each are described individually below.

\section{TCP Phase Quantification and Mapping}

Backscatter electron imaging was used to identify the presence of TCP phases in unetched specimens. This method is particularly suited for this task since compositional differences between the TCP phases and the surrounding matrix ${ }^{[12,17]}$ cause the TCP phases to appear white. This can be seen in Figure 2(a), which shows a typical micrograph obtained in the fusion zone of the as-welded specimen. This imaging technique was used for two objectives:

1. Determination of the volume fraction of TCP phases present in the weld, and

2. Mapping the fusion zones of the as-welded and solution annealed specimens.

The specimens were imaged using an FEI Company Quanta 200 SEM equipped with a 4-quadrant solid-state backscatter electron detector. For TCP phase quantification, 40 micrographs were collected at regular intervals for each specimen at a magnification of $1500 \mathrm{x}$ within the top $4 \mathrm{~mm}$ of the weld. Imaging was restricted to this weld region primarily because it is the most pertinent to material performance from a corrosion point of view, and is also likely to contain the greatest amount of solute. A grayscale threshold was then applied to each of the micrographs, yielding black and white images with the white representing the TCP phases (Figure 2(b)). Image analysis was then 
performed, yielding an area fraction for the TCP phase (white) portion of each image. The average area fraction of TCP phases in each specimen can then be calculated. Since the images were obtained on a regularly spaced grid, the volume fraction of TCP phases is equal to the measured area fraction ${ }^{[20]}$.

The fusion zone of two specimens was mapped: the as-welded specimen and the specimen solution annealed at $1121^{\circ} \mathrm{C}$ for 20 minutes. This was performed by collecting 880 micrographs (for each specimen), and stitching them together to form a collage. The collage layout consisted of 44 rows and 20 columns, with the first row at the top of the weld (last weld pass), and the last row near the center of the weld (first weld pass). The individual micrographs were imaged at 500x, which yielded an actual field of view of approximately $511 \mu \mathrm{m}$ by $441 \mu \mathrm{m}$ for each micrograph. To eliminate the chance of overlap, neighboring images were separated by a stage translation of $520 \mu \mathrm{m}$ and $450 \mu \mathrm{m}$ in the $\mathrm{x}$ and $\mathrm{y}$ directions, respectively. The total area covered during the imaging of both specimens was $10.4 \mathrm{~mm}$ by $19.8 \mathrm{~mm}$.

For each of the two specimens imaged in this manner, two collages were generated. The first was of the micrographs as captured, which allowed the visualization of the complete fusion zone microstructure, while the second was of the micrographs after a grayscale threshold had been applied, yielding a map detailing the locations of the TCP phases within the weld fusion zone. Note: For the second collage, it was limited to the first $75 \%$ of the imaged area (i.e. 33 rows) since the weld fusion zone decreases considerably in size in the subsequent rows.

\section{Crystallographic Orientation Mapping}

Automated EBSD scans ${ }^{[21,22]}$ were performed on each specimen to map their microstructures and determine the crystallographic texture of the fusion zones after the solution annealing treatments. This was carried out using a TexSEM Laboratories OIM 4 system equipped with a Peltier cooled CCD camera. Specimens were tilted to $70^{\circ}$ in the SEM chamber, and an accelerating voltage of $30 \mathrm{kV}$ and a beam current of $98 \mu \mathrm{A}$ were used in spot mode.

Due to the size of the area of interest, a combination of beam and stage translations were used during the scans. Data were collected on a square grid, with grid step sizes of $12 \mu \mathrm{m}$ to $30 \mu \mathrm{m}$ (depending on the specimen's grain size), and typically covered an area of approximately $9 \mathrm{~mm}$ by $20 \mathrm{~mm}$. In order to align the EBSD scans with the micrograph collages for the as-welded specimen and the specimen annealed at $1121^{\circ} \mathrm{C}$ for 20 minutes, two fiducial marks (one at either end of the weld fusion zone) were used. 


\section{RESULTS}

The results of the TCP volume fraction measurements are listed in Table II. It can be seen that TCP phases are present in only three of the seventeen specimens: as-welded, solution annealed at $1075^{\circ} \mathrm{C}$ for 20 minutes, and solution annealed at $1121^{\circ} \mathrm{C}$ for 20 minutes. Since the volume fractions measured were very small $(<1 \%)$ and the TCP phases are inhomogeneously dispersed, the relative error associated with the values is quite high. It is interesting to note that while the results found follow the same trends observed in previous work in that the TCP phase content increases during solution annealing in the top region of the weld ${ }^{[17]}$, it is known that for the specimen

treated at $1121^{\circ} \mathrm{C}$ for 20 minutes the TCP phase content within the entire weld actually decreases ${ }^{[18]}$. As such, the values determined could only be used as an indication of the presence of TCP phases. It is important to note that for the specimens with zero volume fractions, the lack of TCP phase observations does not fully eliminate the possibility of their existence, rather it indicates that if any are present, they are significantly smaller than $0.25 \mu \mathrm{m}$ (the resolution of the instrument).

Figures 3(a) and 3(b) illustrate the micrograph collages generated for the as-welded specimen and the specimen annealed at $1121^{\circ} \mathrm{C}$ for 20 minutes, respectively. Figures 4(a) and 4(b) are the corresponding collages after a threshold and inversion (so that the TCP phases appear black instead of white) had been applied to the micrographs, indicating the location of the TCP phases. It is clear that the location of the TCP phases follows the weld pass geometry. It can also be seen that while the TCP phase distribution is spatially homogeneous (at the apparent length scale) near the top of the weld, there is a distinct banding structure in the first few weld passes. Note: In Figures 4(a) and 4(b) the TCP phases were artificially coarsened for clarity, and the sizes observed are not to scale.

Figure 5 presents the results of the EBSD scans for the as-welded specimen as well as the specimens annealed for 20 minutes at all four temperatures as color-coded Inverse Pole Figure (IPF) maps. The colors correspond to the crystallographic directions parallel to the specimen [010] axis (towards the top of the page). This direction was selected since it is parallel (and opposite) to the heat flow axis present during the welding process. In Figure 5(d) projections of $\{100\}$ plane normals are superimposed as black lines on a portion of the IPF map shown in Figure 5(a). This clearly illustrates that the dendrites have grown following the traditionally observed $\{100\}$ plane normal directions. It can also be seen in Figures 5(b), (c), (e), and (f) that while the specimens treated at $1075{ }^{\circ} \mathrm{C}$ and $1121^{\circ} \mathrm{C}$ are still in the process of recrystallization, the specimen treated at $1200^{\circ} \mathrm{C}$ appears fully recrystallized and the 
specimen treated at $1300^{\circ} \mathrm{C}$ possesses coarsened grains. It is also evident that the recrystallization behavior in the $1075^{\circ} \mathrm{C}$ and $1121^{\circ} \mathrm{C}$ specimens is closely related to the weld pass geometry.

Results on the observed microstructure are also listed in Table II for each solution annealing condition. Full recrystallization (>95\%) of the columnar dendrites in the fusion zone was observed in the specimens annealed for 168 hours at $1075^{\circ} \mathrm{C}, 24$ hours at $1121^{\circ} \mathrm{C}$, and 20 minutes at $1200^{\circ} \mathrm{C}$. Backscattered electron SEM micrographs of these specimens are shown in Figure 6. In the specimen aged at $1300^{\circ} \mathrm{C}$, full recrystallization must have occurred well before 20 minutes, since rapid grain growth and coarsening behavior was observed at the 20 minute mark. Also observed is marked grain coarsening near the fusion zone boundary of the specimens annealed at $1075^{\circ} \mathrm{C}$ for 168 hours, $1121^{\circ} \mathrm{C}$ for durations of 72 hours and greater, $1200^{\circ} \mathrm{C}$ for durations of 24 hours and greater, and for all the specimens annealed at $1300^{\circ} \mathrm{C}$.

The texture evolution of the fusion zone as a function of time and temperature of solution annealing is shown in Figure 7 as [010] IPF plots, calculated using $3^{\circ}$ bins with $3^{\circ}$ full width-half max Gaussian smoothing. It can be seen that for the as-welded specimen, the peak at [001] verifies the observation in Figure 5(d) regarding the preferred dendrite growth direction. It can also be seen that this peak redistributes in multiple ways for all the solution annealed specimens. A noteworthy observation is for specimens annealed for 20 minutes, where a progressive evolution from an [001] texture to an [101] texture can be seen between $1075^{\circ} \mathrm{C}$ and $1200^{\circ} \mathrm{C}$.

\section{DISCUSSION}

In this study, we are concerned with two aspects of microstructural evolution: intermetallic TCP phase dissolution and recrystallization behavior. Typically, the motivation for solution annealing Alloy 22 is the dissolution of the secondary TCP phases, since Alloy 22 is primarily utilized in commercial applications requiring corrosion resistance and the presence of these phases has been shown to adversely affect these properties ${ }^{[15]}$. However, the effect of solution annealing treatments on recrystallization can also be important, especially if a preferred texture evolves during the process as demonstrated in recent correlations between grain orientation and corrosion rates in Inconel $60{ }^{[23]}$. In this section, three aspects of microstructural evolution during solution annealing will be discussed. (1) The relationship between solution annealing temperature and the rates of TCP phase dissolution and recrystallization, and their effect on resultant texture, (2) how residual tensile stresses and solute segregation during weld solidification appear to dictate recrystallization locations, and (3) the dependence of TCP phase dissolution on annealing duration. 


\section{A. Effect of TCP Phase Dissolution Rate on Recrystallization Texture}

The dissolution of secondary phases in multi-component alloys is primarily limited by the diffusion coefficients of the phase's constituents ${ }^{[24]}$. Although these coefficients can be limited by local variations in composition and stresses, their values are directly linked to temperature. Similarly, the rate of recrystallization is highly dependent on temperature and residual strain (i.e. amount of stored energy or cold work). On the other hand the presence of secondary phases is known to limit grain recrystallization and growth due to pinning of the grain boundaries, and can affect the recrystallization texture observed ${ }^{[25]}$.

In this study, we have the TCP phase dissolution occurring simultaneously with the recrystallization process. It can then be inferred that if the solution annealing conditions used are such that the time required for recrystallization is much longer than the time required for secondary phase dissolution, no interactions will occur between the recrystallized grains and the secondary phases. However, if the time required for recrystallization is comparable to the time required for secondary phase dissolution, the interactions between the recrystallized grains and the secondary phases can play a major role in the resultant microstructure and texture. This can be seen when comparing the microstructures of the three fully recrystallized specimens in this study, which are the specimens annealed for 168 hours at $1075^{\circ} \mathrm{C}, 24$ hours at $1121^{\circ} \mathrm{C}$, and 20 minutes at $1200^{\circ} \mathrm{C}$.

For the specimen annealed at $1075^{\circ} \mathrm{C}$, TCP phase dissolution occurs after 24 hours, well before recrystallization is complete. Examination of Figure 7 for this specimen shows broad, weakened peaks in the IPF plots with no preferred texture. This also appears to be the case for the specimen annealed at $1121^{\circ} \mathrm{C}$ for 24 hours, although portions of the SEM image collage Figure 3(b) show that while TCP deficient regions contain recrystallized grains, other regions do not recrystallize as seen in Figure 8(a) and (b), respectively. Also, in other areas recrystallization occurs before or during TCP phase dissolution as seen in Figure 8(c). Ultimately however, considering that the evolution of the $1121^{\circ} \mathrm{C}$ IPF plots is similar to that of the $1075^{\circ} \mathrm{C}$ specimens, it can be reasoned that the majority of TCP phase dissolution occurs before recrystallization is complete.

In contrast, a $<101>$ texture is developed parallel to the original dendrite growth directions in the specimen recrystallized at $1200^{\circ} \mathrm{C}$. The fact that this texture remained in the specimens annealed for longer periods of time at $1200^{\circ} \mathrm{C}$ indicates that an event occurring during the early stages of annealing is responsible for this preferred orientation. It is most likely that this texture appears due to TCP phase dissolution and recrystallization occurring 
concurrently at $1200^{\circ} \mathrm{C}$ such that the interactions between the recrystallizing grains and the TCP phases force the grains to grow in preferred orientations.

To confirm this hypothesis, the texture of recrystallized regions of the weld annealed at $1121^{\circ} \mathrm{C}$ for 20 minutes, such as those shown in Figure 8 (c), is used. It can be seen in Figure 8(c) that fully recrystallized grains form alongside TCP phases. This type of microstructure then is likely very similar to that assumed to have occurred in the early stages of the $1200^{\circ} \mathrm{C}$ anneal. For texture analysis, it was necessary to partition the EBSD data into two datasets: one for the recrystallized grains and one for the original weld dendrites. This was achieved by using the grain shape aspect ratio as the distinguishing parameter since the columnar dendrites have a much smaller aspect ratio compared to the equiaxed recrystallized grains, and the resulting IPF plots are shown in Figure 9. Figure 9 shows that the columnar grains retain the expected $<001>$ texture while the recrystallized grains possess a moderate $<101>$ texture. It should be noted that the strength of this $<101>$ peak is less than that observed for the $1200^{\circ} \mathrm{C}$ specimens, presumably because the interaction between the TCP phases and the recrystallizing grains is not the sole active mechanism at $1121^{\circ} \mathrm{C}$.

\section{B. Effect of Stresses and Compositional Variations on Recrystallization}

Examination of the microstructure of the specimens annealed at $1075^{\circ} \mathrm{C}$ and $1121^{\circ} \mathrm{C}$ for 20 minutes shows the inhomogeneity of the recrystallization process at these temperatures. It has been known for some time that of the many factors that influence recrystallization, stored energy and chemical composition variations play a large role. It is also believed that these are the two pertinent factors in dictating where recrystallization first occurs. Let us first consider the role of stored energy. While traditionally stored energy is usually in the context of cold work and deformation, in welds it is manifested as residual thermal stresses. Recently, the residual stress in the cross-section of Alloy 22 double-U welds in thick plates has been mapped ${ }^{[26]}$ using the surface contour method ${ }^{[27]}$. The residual stress distribution is illustrated in Figure 10, and it can be seen that the stresses near the top of the weld are 4 to 5 times greater than near the center.

Consideration of the chemical composition variations begins with consideration of the segregation that occurs during weld solidification. Since the weld solidifies dendritically, understanding of dendritic solidification can be applied. The TCP phase distributions (shown in Figure 4), as well as recent work of Pan et. al ${ }^{[17]}$, provides evidence that microsegregation occurs during the solidification of individual weld passes. It is also likely that macrosegregation occurs during solidification of multiple pass welds. If we consider the initial weld pass, it is reasonable to assume (considering the high solute content of the alloy) that at the conclusion of the welding pass, the 
final solidified layer is richer in solute than the columnar grains that grew during solidification. This layer is then subsequently re-melted during the next weld pass, increasing the relative solute content in the next pass while decreasing the solute at the end of the previous pass. Since this process is repeated (in this case 9 times per Ugroove), it is likely that the net solute content increases in each subsequent weld pass. Furthermore, the regions within any given weld pass that are the first to solidify typically have the lowest solute content ${ }^{[26]}$.

In Figure 11, the solute distribution suggested above is presented schematically as a function of location within the weld. If we separate the weld into four regions, A through $\mathrm{D}$, and consider the tensile stress distribution shown in Figure 10 as well as the proposed solute distributions, we can broadly characterize the regions as follows:

Region A: Low solute concentration, low residual stress.

Region B: Moderate solute concentration, moderate residual stress.

Region C: Moderate/High solute concentration, high residual stress.

Region D: Highest solute concentration, high residual stress.

Of the two phenomena involved in recrystallization, nucleation and growth, the effect of stress is primarily related to the nucleation rate. This rate is related to the strain energy in the material such that an increase in the residual stress causes an increase in nucleation rate ${ }^{[29,30]}$.

The effect of chemical composition on nucleation has generally been thought of as recrystallized grain boundary motion inhibition due to solute drag at the grain boundaries. As such it is primarily related to limiting the recrystallized grain growth rate, and it is well established that lower solute concentrations typically improve recrystallized grain growth rates ${ }^{[31-33]}$.

Based on the observations of the specimens annealed at $1075^{\circ} \mathrm{C}$ and $1121^{\circ} \mathrm{C}$ for 20 minutes it was observed that recrystallization occurs at the root pass of the weld (Region A) and near pass interfaces in Regions B \& C, especially closer to the fusion line. In light of the previous statements, we can summarize the recrystallization behavior of the weld by region as follows:

Region A: The recrystallization observed in this region is most likely due to the effect of lower solute concentrations on growth kinetics. This is clearest in the $1075^{\circ} \mathrm{C}$ specimen where the majority of the growth is in this region.

Region B: Recrystallization observed in this region occurs in two distinct areas: near the fusion line and in well-defined bands across the weld. The former is likely due to increasing solute concentrations near the weld centerline. The latter is likely due to the local decrease in solute concentrations in the weld pass regions re-melted during the following weld pass. 
Region C: Despite the increased solute content in this region, recrystallization is observed in the $1121^{\circ} \mathrm{C}$ specimen. The majority of the recrystallization occurs at the top of this region where residual stresses are maximum, promoting the nucleation of recrystallized grains.

Region D: No recrystallization is observed in this region in earlier stages of the anneal at the temperatures of $1075^{\circ} \mathrm{C}$ and $1121^{\circ} \mathrm{C}$ due to the high solute content present, although nuclei may have formed due to the large residual stress but were unable to grow due to the high solute content. It is only after extended anneal times does this region recrystallize, probably due to TCP phase dissolution and homogenization taking place. At the temperatures of $1200^{\circ} \mathrm{C}$ and $1300^{\circ} \mathrm{C}$ this region recrystallizes with the rest of the weld due to the decreased effect of solute drag with the increased temperature.

Overall, the weld passes that experience recrystallization first are those that are either near the first cap weld pass (under the highest residual tensile stress) or those closer to the root pass (lower solute concentration). It can be inferred that for the weld pass interfaces displaying no recrystallization, the driving force for recrystallization due to the presence of the residual tensile stresses is not strong enough to overcome the increased activation energies caused by the presence of higher solute concentrations. It is suggested that an areal chemical composition map be performed across the same area of weld with a similar spatial resolution to verify this hypothesis.

\section{Effect of Solution Annealing Duration}

The most comprehensive body of work to date on the effect of solution annealing in Alloy 22 welds has been by Pan et. $a l^{[16]}$. In that study, the lowest solution annealing temperature was $1125^{\circ} \mathrm{C}$ with the longest duration being 1 hour. It was concluded that the duration was not long enough for TCP phase dissolution. It was also believed, based on volume fraction measurements, that the TCP phases grew at that temperature. Another study ${ }^{[17]}$ showed that annealing at $1121^{\circ} \mathrm{C}$ for 20 minutes caused TCP phase coarsening, but decreased the total TCP phase volume fraction in the fusion zone by $5 \%$ relative to the as-welded condition. Considering that in the work presented here full TCP phase dissolution was observed after annealing for 24 hours at $1121^{\circ} \mathrm{C}$, it is most likely that the increase in TCP phases reported by Pan et. al is due to a combination of localized coarsening and weld inhomogeniety. A follow-up study at intermediate times (e.g. 3 hours) would be necessary for a definitive explanation of the dissolution process of the TCP phases.

Pan et. al also reported that treatment at $1200^{\circ} \mathrm{C}$ and $1300^{\circ} \mathrm{C}$ for 15 minutes yielded a microstructure with increased TCP phase content. In this work, treatment for 20 minutes at the same temperatures yielded TCP phase- 
free microstructures, although at $1300^{\circ} \mathrm{C}$ similar abnormal grains were observed. Assuming the differences in experimental methods to measure TCP phases (etching versus backscatter electron imaging) do not play a factor, it appears that the extra 5 minutes at temperature used in this study are sufficient to fully dissolve the TCP phases.

\section{CONCLUSIONS}

Specimens of Alloy 22 multi-pass gas-tungsten-arc-welds were solution annealed at $1075^{\circ} \mathrm{C}, 1121^{\circ} \mathrm{C}, 1200^{\circ} \mathrm{C}$ and $1300^{\circ} \mathrm{C}$ for durations between 20 minutes to 168 hours. Seventeen specimens in total, including one as-welded specimen, were examined in cross section using scanning electron microscopy as well as electron backscatter diffraction. From the experimental evidence gathered, the following statements can be made to summarize the work:

- Similar to many other cubic metals, Alloy 22 welds solidify preferentially along $<100>$ directions.

- Intermetallic TCP phase dissolution can be achieved by solution annealing for 24 hours at either $1075^{\circ} \mathrm{C}$ or $1121^{\circ} \mathrm{C}$, or 20 minutes at either $1200^{\circ} \mathrm{C}$ or $1300^{\circ} \mathrm{C}$.

- Full recrystallization of Alloy 22 welds can be achieved by solution annealing for 168 hours at $1075^{\circ} \mathrm{C}$, 24 hours at $1121^{\circ} \mathrm{C}$, and 20 minutes at $1200^{\circ} \mathrm{C}$. At $1300^{\circ} \mathrm{C}$, annealing for 20 minutes produces a microstructure with a abnormal grain sizes in the fusion zone, indicating a significant driving force for grain growth and coarsening.

- Of the fully recrystallized specimens observed, the specimen annealed at $1200^{\circ} \mathrm{C}$ for 20 minutes yielded the most homogeneous grain size distribution.

- Study of specimens with partial recrystallization showed that recrystallization occurs initially in regions near the root pass of the weld. Subsequently, recrystallization occurs within regions at the interfaces between weld passes. The sequence of recrystallization suggests that solute segregation seems to play a dominant role in controlling recrystallization.

- Texturing of the recrystallized grain structure can be achieved if the time required for the dissolution of the intermetallic TCP phases is comparable to the time required for full recrystallization. It is reasoned that this is the cause of the texture evolution of the specimens aged at $1200^{\circ} \mathrm{C}$, which shows a preferred $<101>$ texture in the direction of the original $<100>$ dendrite growth direction. It is also reasoned that this preferred $<101>$ texture is due to the crystallographic constraints imposed by the TCP phases on the recrystallizing grains during the recrystallization process. 


\section{ACKNOWLEDGMENTS}

Michael M. McGregor is gratefully acknowledged for his assistance in sample treatment and preparation. Raul B. Rebak is acknowledged for technical discussions. Adrian DeWald and Michael Hill are acknowledged for their permission to use Figure 10. This work was performed under the auspices of the U. S. Department of Energy by the University of California Lawrence Livermore National Laboratory under contract N W-7405-Eng-48. This work is supported by the Office of Civilian Radioactive Waste Management (OCRWM), U.S. Department of Energy.

\section{DISCLAIMER}

This document was prepared as an account of work sponsored by an agency of the United States Government. Neither the United States Government nor the University of California nor any of their employees, makes any warranty, express or implied, or assumes any legal liability or responsibility for the accuracy, completeness, or usefulness of any information, apparatus, product, or process disclosed, or represents that its use would not infringe privately owned rights. Reference herein to any specific commercial product, process, or service by trade name, trademark, manufacturer, or otherwise, does not necessarily constitute or imply its endorsement, recommendation, or favoring by the United States Government or the University of California. The views and opinions of authors

expressed herein do not necessarily state or reflect those of the United States Government or the University of California, and shall not be used for advertising or product endorsement purposes.

\section{REFERENCES}

1. ASTM Standard B 575-04, ASTM International, West Conshohocken, PA, 2004.

2. D. Dunn, G. Cragnolino, and N. Sridhar: in Scientific Basis for Nuclear Waste Management XXIII, Materials Research Society, Warrendale, PA,2000, vol. 608, pp. 89.

3. R. Rebak, N. Koon, J. Dillman, and P. Crook: Corrosion/2000, NACE International, Houston, TX, 2000, Paper 181.

4. P. Manning and J. Schöbel: Werkstoffe und Korrosion, 1986, vol. 37, pp. 137.

5. I. Asphahani: The Arabian Journal for Science and Engineering, 1989, vol. 14, No.2, pp. 317.

6. R. Rebak: in Passivity and Localized Corrosion, The Electrochemical Society, Pennington, NJ, 1998, vol. 97-26, pp. 1001.

7. R. Rebak and N. Koon: Corrosion/98, NACE International, Houston, TX, 1998, Paper 153.

8. K. Gruss, G. Cragnolino, D. Dunn, and N. Sridhar: Corrosion/98, NACE International, Houston, TX, 1998, Paper 149. 
9. R. Rebak and P. Crook: in Critical Factors in Localized Corrosion III, The Electrochemical Society, Pennington, NJ, 1999, vol. 98-17, pp. 289.

10. T.S.E. Summers, M.A. Wall, M. Kumar, S.J. Matthews, and R.B. Rebak: in Scientific Basis for Nuclear Waste Management XXII, Materials Research Society, Warrendale, PA, 1999, vol. 556, pp. 919.

11. R. Rebak, and P. Crook: in Transportation, Storage, and Disposal of Radioactive Materials, ASME International, New York, NY, 2002, vol. PVP-449, pp. 111.

12. M.J. Cieslak, T.J. Headley, and A.D. Romig: Metall. Trans. A, 1986, vol. 17A, pp. 2035.

13. J.S. Ogborn, D.L. Olson, and M.J. Cieslak: Mat. Sci. Eng. A, 1995, vol. 203, pp. 134.

14. T.S.E. Summers, R.B. Rebak, and R.R. Steely: LLNL, UCRL-JC-137727, 2000 TMS Fall Meeting, St. Louis, MO.

15. T.S.E. Summers, R.B. Rebak, T.A. Palmer, and P. Crook: in Scientific Basis for Nuclear Waste Management XXV, Materials Research Society, Warrendale, PA, 2002, vol. 713, pp. 45.

16. Haynes International, Hastelloy C-22 Alloy. Kokomo, Indiana, 1997, pp. 16.

17. Y.-M. Pan, D.S. Dunn, and G.A. Cragnolino: Metall. Mater. Trans. A, 2005, vol. 36A, pp.1143.

18. B.S. El-Dasher, and S.G. Torres: Pressure Vessel and Piping Conference 2005, ASME International, New York, NY, Paper No. PVP-2005-71665.In Press

19. ASME SFA-5.14, ERNiCrMo-10, ASME International , New York, NY, 2004, sec. II, pp. 325.

20. J.E. Hilliard: in Quantitative Microscopy, 1968, McGraw-Hill, New York, NY.

21. S.I. Wright, and B.L. Adams: Metall. Trans. A, 1992, vol. 23A, pp. 759.

22. B.L. Adams, S.I. Wright, and K. Kunze: Metall. Trans. A, 1993, vol. 24A, pp. 819.

23. C.A. Shuh, K. Anderson, and C. Orme: Surf. Sci., 2003, vol. 544, pp. 183.

24. D.A. Porter and K.E. Easterling: in Phase Transformations in Metals and Alloys, $2^{\text {nd }}$ ed., Chapman \& Hall, London, UK, 1996, pp. 68.

25. L. Zhuang, J. Bottema, P. Kaasenbrood, W.S. Miller, and P. De Smet: Mat. Sci. Forum, vols. 217-222, pp. 487.

26. A.T.Dewald, J.E. Rankin, M.R. Hill, M.J. Lee, and H. Chen: J. Eng. Mater.Tech., 2004, vol. 126, pp. 465.

27. M.B. Prime: ASME J. Eng. Mater. Tech. 2001, vol. 123, pp.162.

28. R.E. Reed-Hill: in Physical Metallurgy Principles, PWS-Kent Publishing, Boston, MA, 1973, pp. 583.

29. D. Turnbull and J.C. Fisher: J. Chem. Phys., 1949, vol. 17, pp.71. 
30. P. Cotterill and P.R. Mould: in Recrystallization and Grain Growth in Metals, John Wiley and Sons, New York, NY, 1976, pp. 62.

31. K. Lücke and K. Detert: Acta Met., 1957, vol. 5, pp. 628.

32. P. Gordon and R.A. Vandermeer: Trans. Met. Soc. AIME, 1962, vol. 224, pp. 917.

33. J.W. Cahn, Acta Met., 1962, vol. 10, pp. 789. 


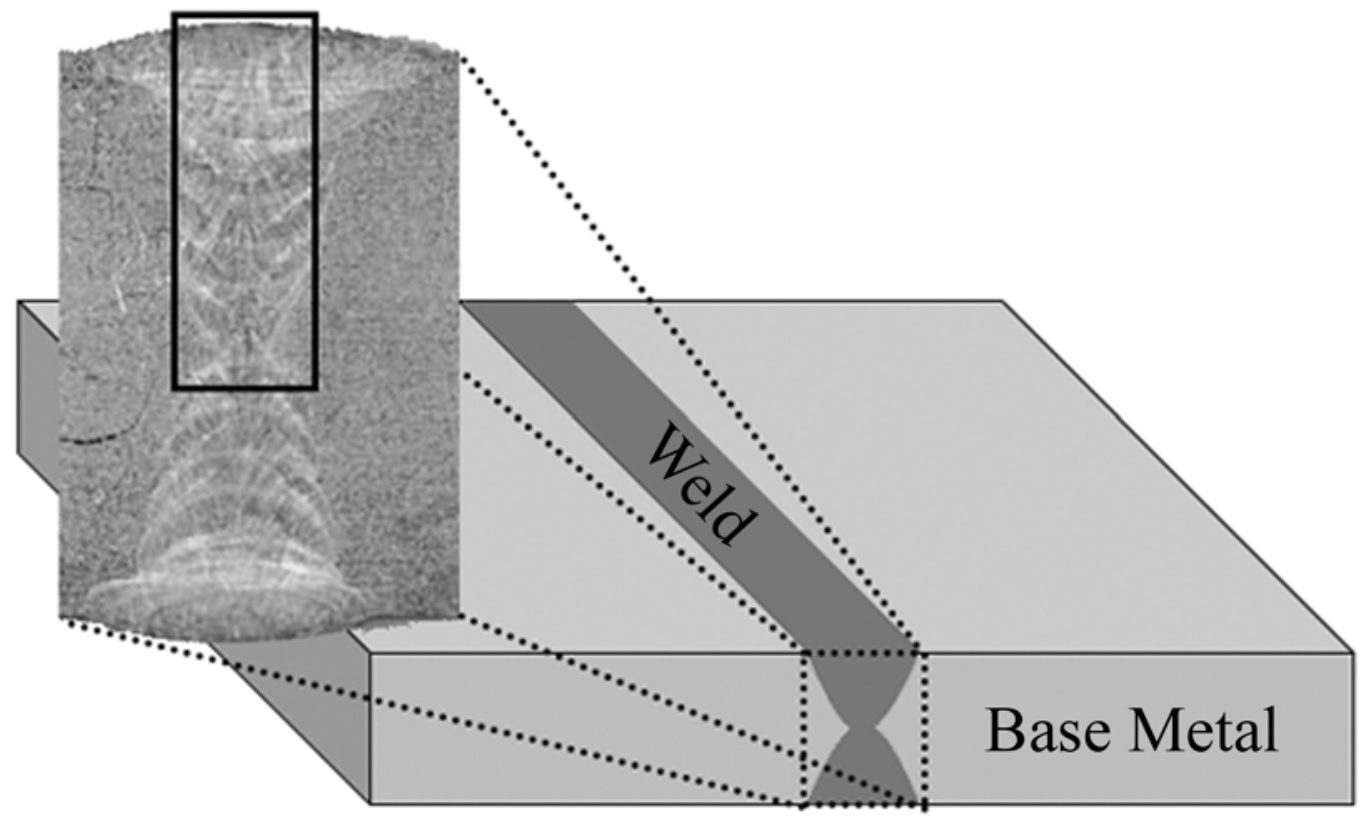

Figure 1. Schematic of weld cross-section showing region of weld examined (box). 

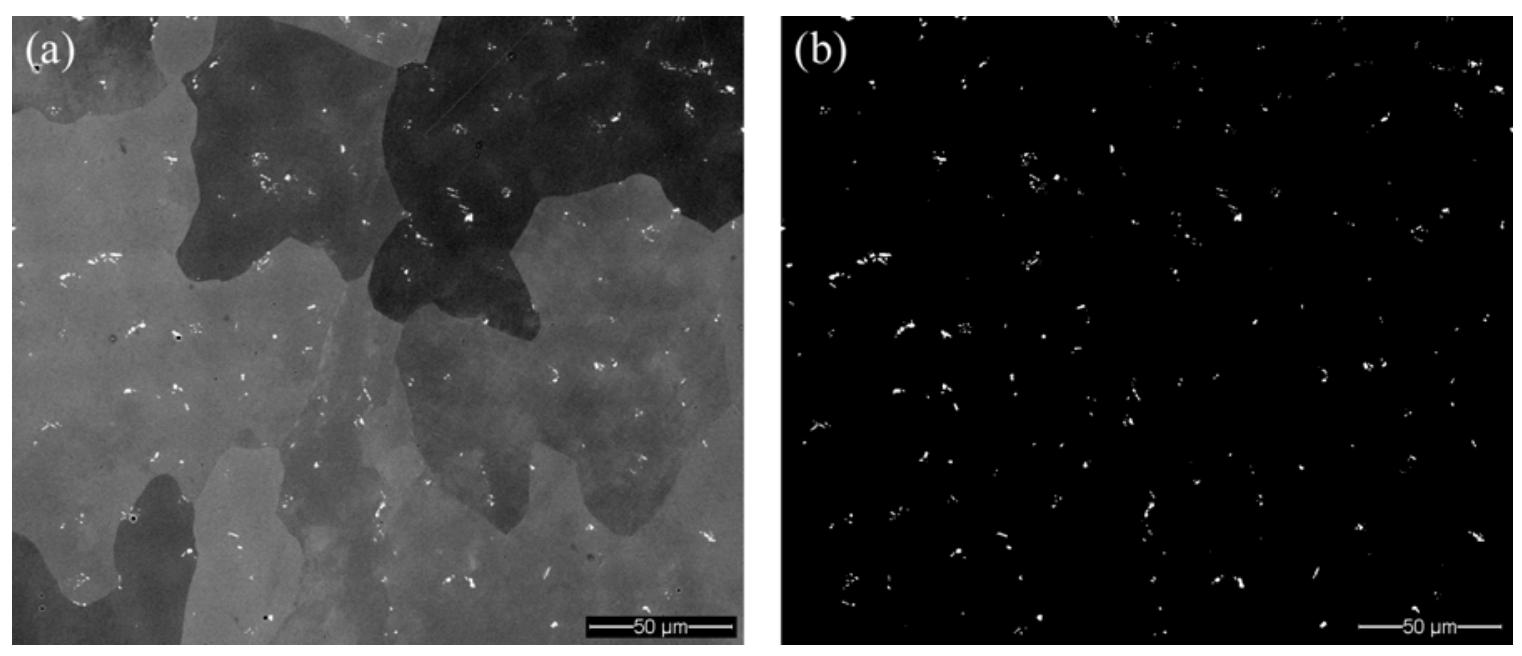

Figure 2. (a) Typical backscattered electron SEM micrograph captured in the fusion zone of the as-welded specimen. Due to compositional differences, TCP phases appear white. (b) Thresholded image of Figure 2(a). 

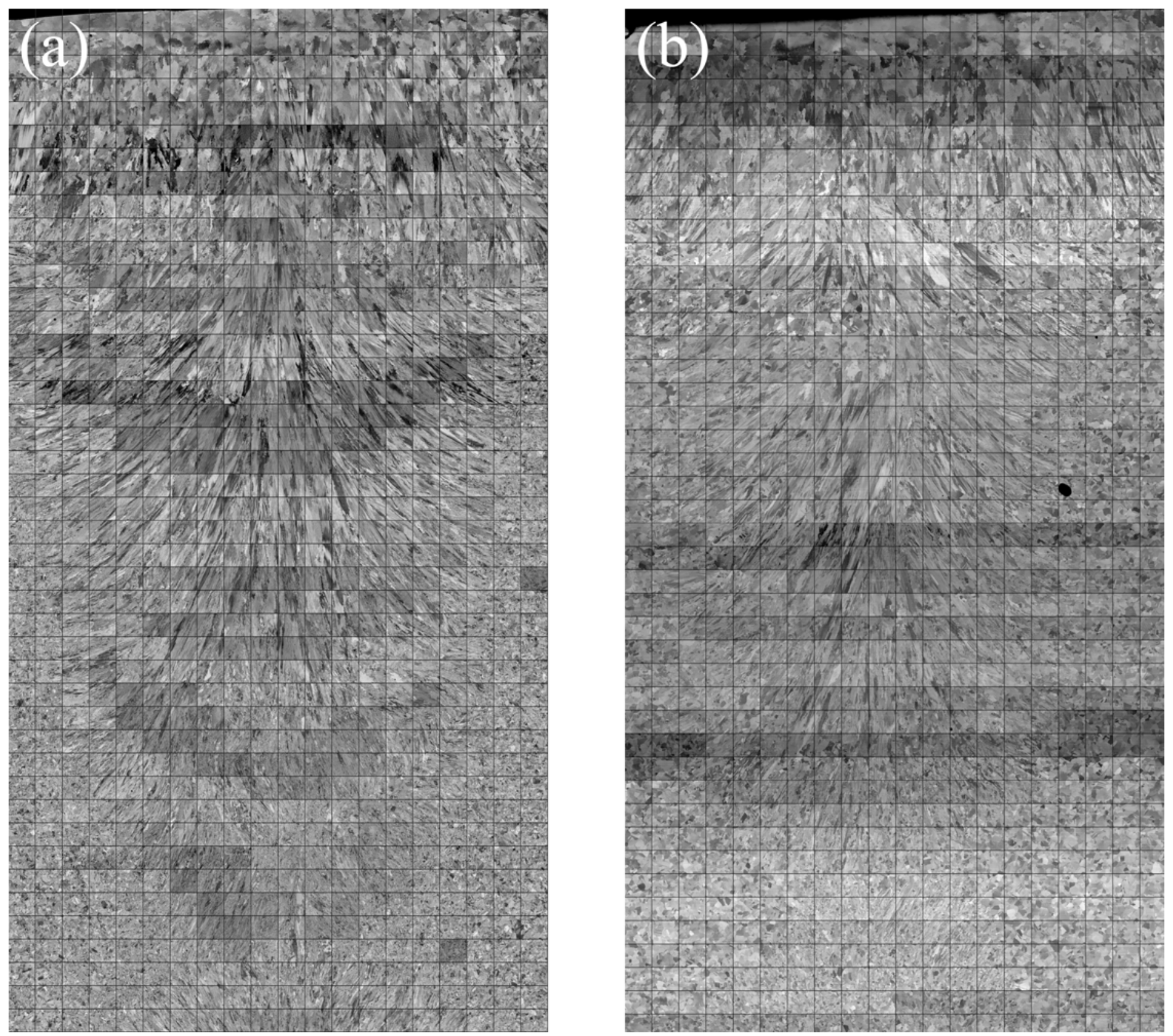

Figure 3. Collages formed by joining 880 SEM backscattered electron micrographs of the (a) as-welded specimen and (b) the specimen solution annealed at $1121^{\circ} \mathrm{C}$ for 20 minutes. 

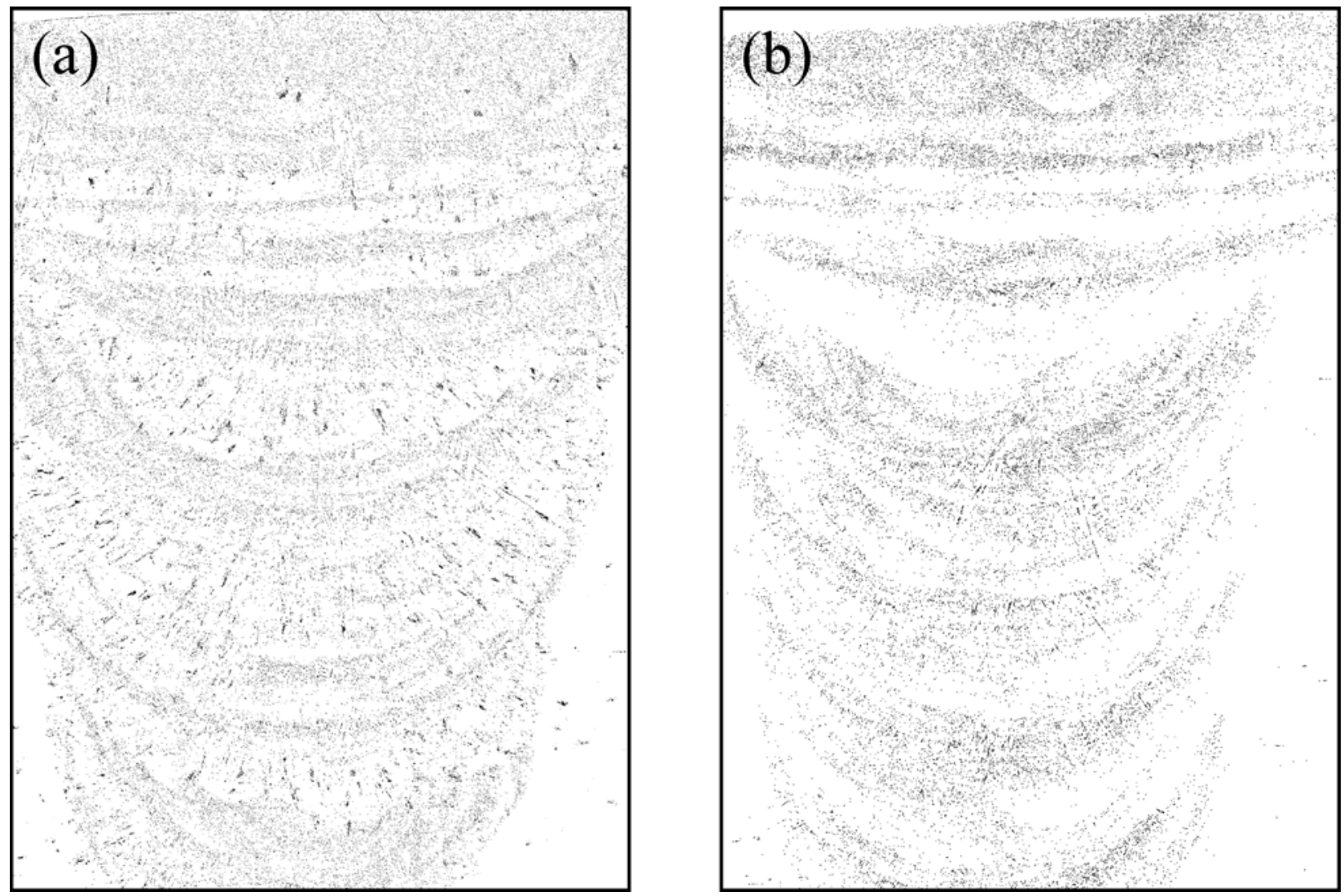

Figure 4. Location of TCP phases in the (a) as-welded specimen and (b) the specimen annealed at $1121^{\circ} \mathrm{C}$ for 20 minutes as determined from the collages shown in Figure 3 . Note that the above images represent the top $3 / 4$ of the collages shown in Figure 3, and that the sizes of the TCP phases have been coarsened for clarity. 

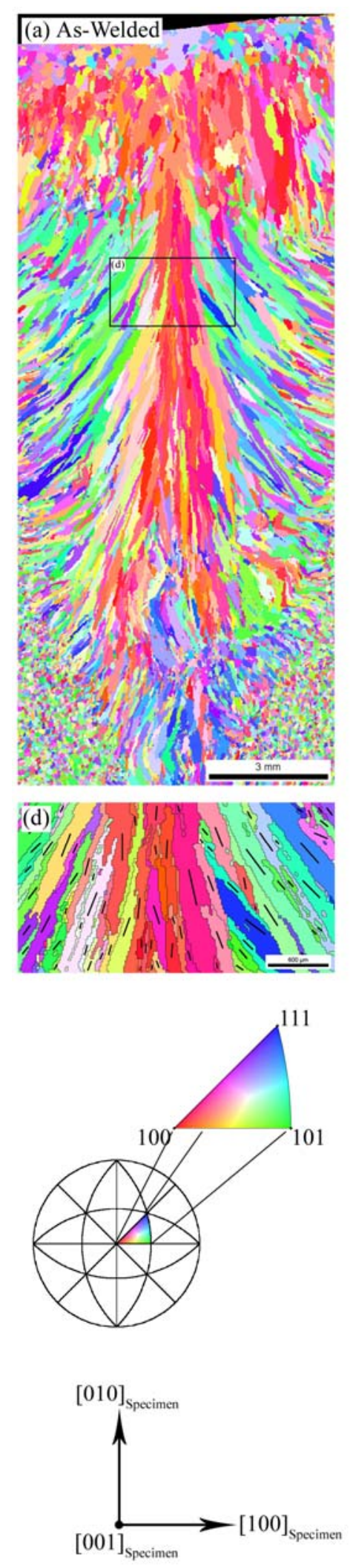
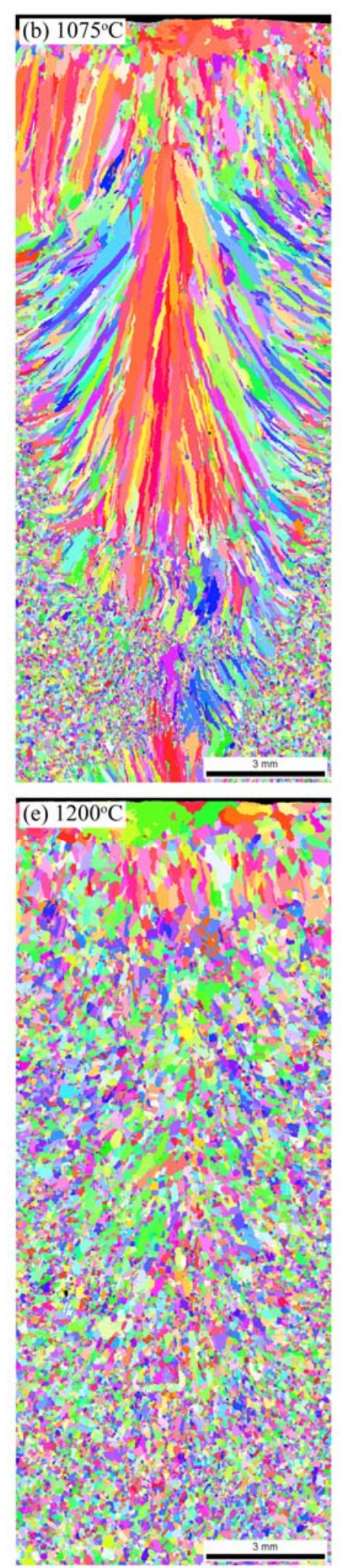
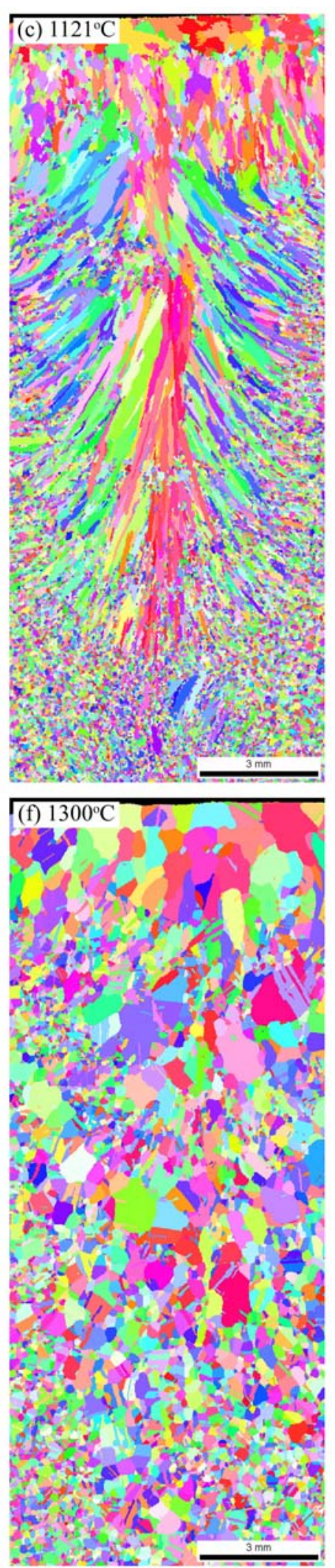

Figure 5. Inverse Pole Figure maps of (a) the as-welded specimen and the specimens annealed for 20 minutes at (b) $1075^{\circ} \mathrm{C}$, (c) $1121^{\circ} \mathrm{C}$, (e) $1200^{\circ} \mathrm{C}$, and (f) $1300^{\circ} \mathrm{C}$. The colors represent the crystallographic plane normals parallel and opposite the heat flow direction during solidification (towards top of the page). Figure 5(d) illustrates the projections of the $<100>$ plane normals in the columnar grains of the as-welded specimen. 

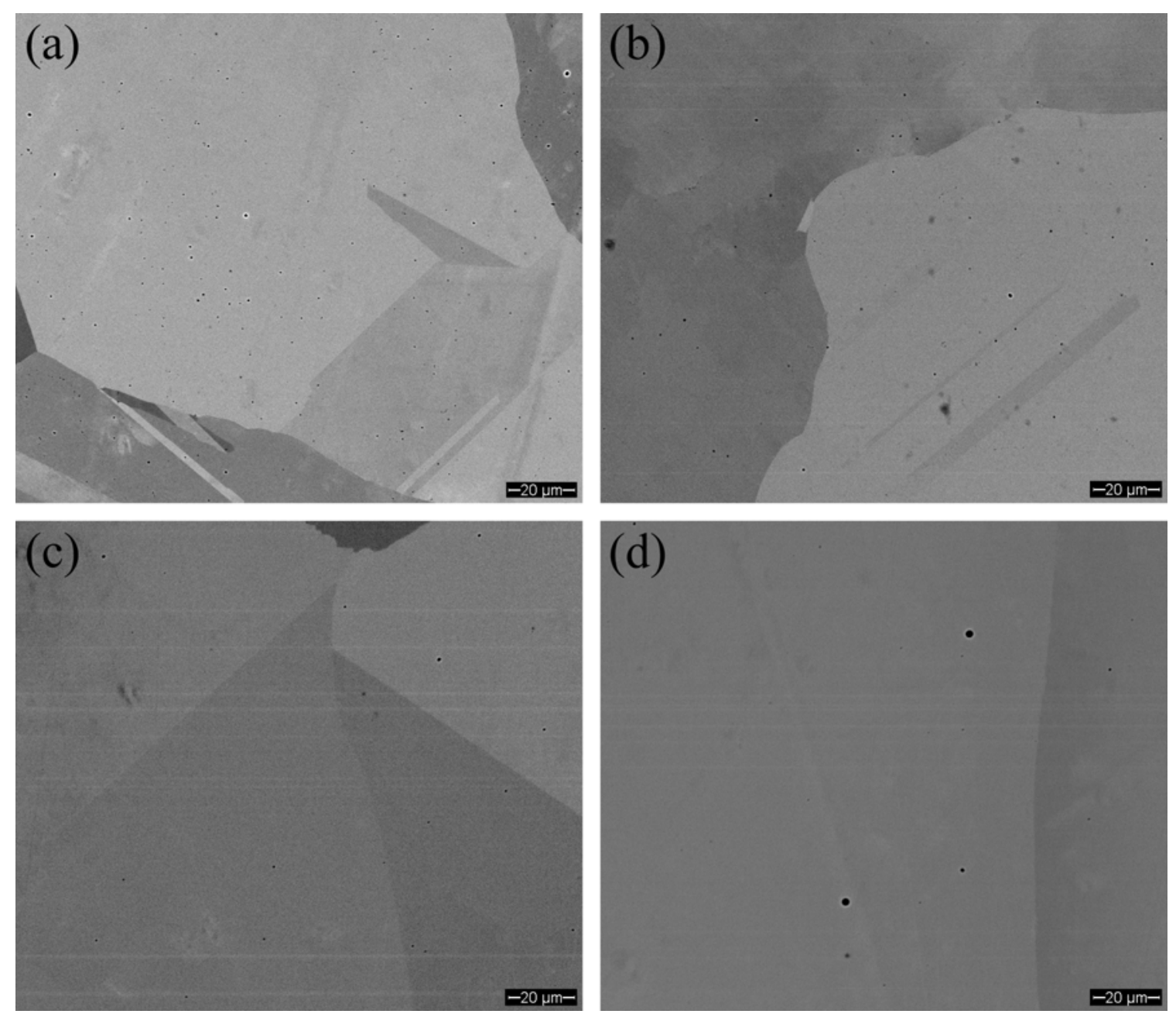

Figure 6. Backscattered electron SEM micrographs of specimens fully recrystallized captured at $1500 x$. Solution annealing was performed for (a) 168 hours at $1075^{\circ} \mathrm{C}$, (b) 24 hours at $1121^{\circ} \mathrm{C}$, (c) 20 minutes at $1200^{\circ} \mathrm{C}$, and (d) 20 minutes at $1300^{\circ} \mathrm{C}$. 

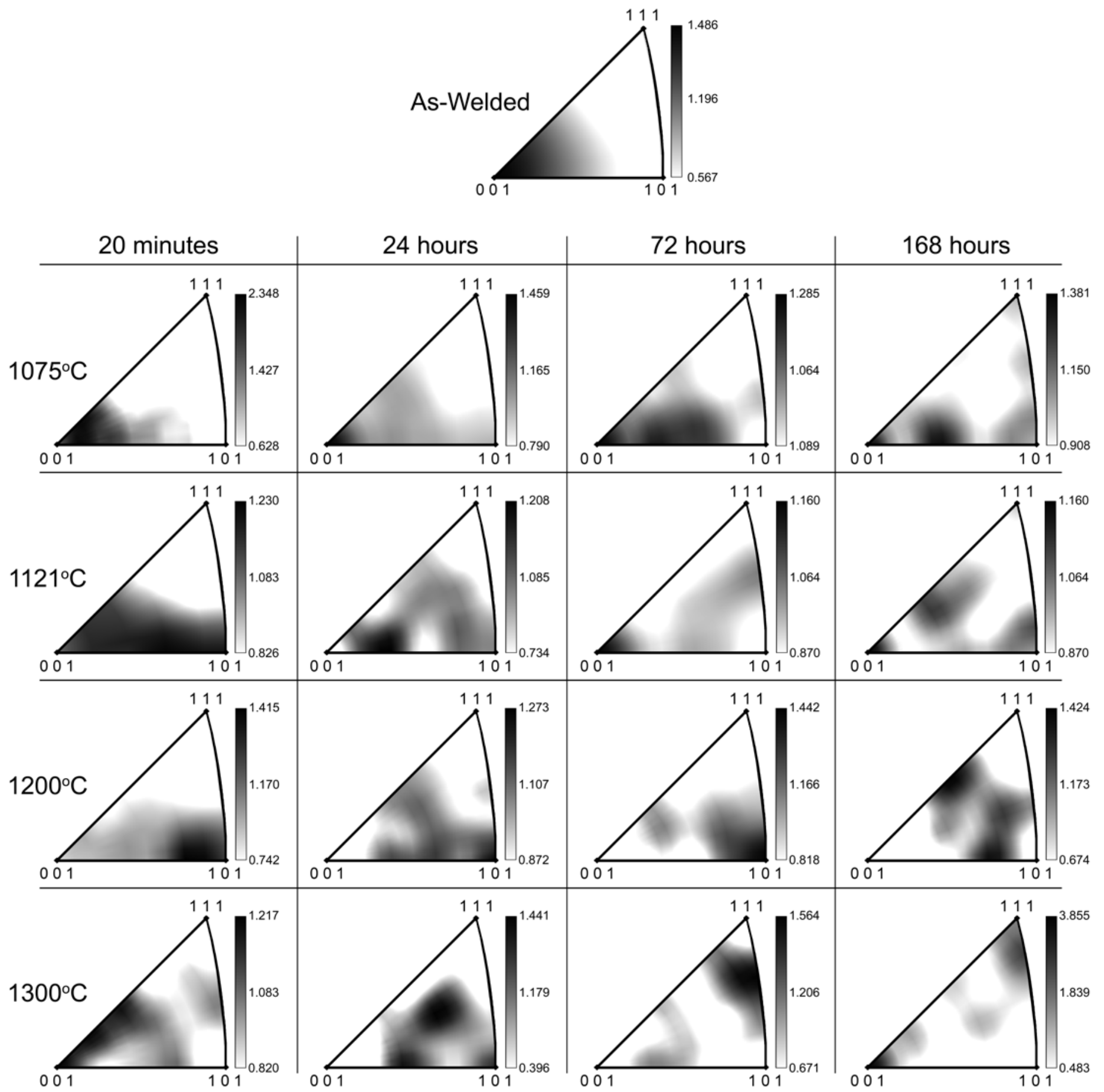

Figure 7. Inverse Pole Figure plots of the crystallographic plane normals parallel to the heat flow direction during solidification for all the specimens examined in this study. 


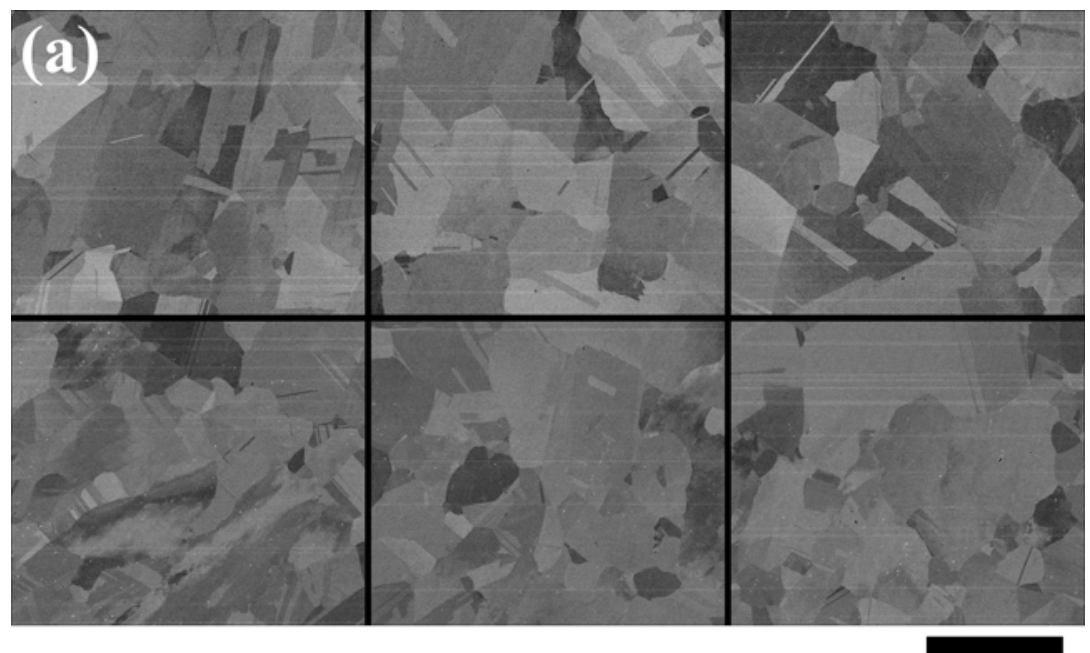

$200 \mu \mathrm{m}$
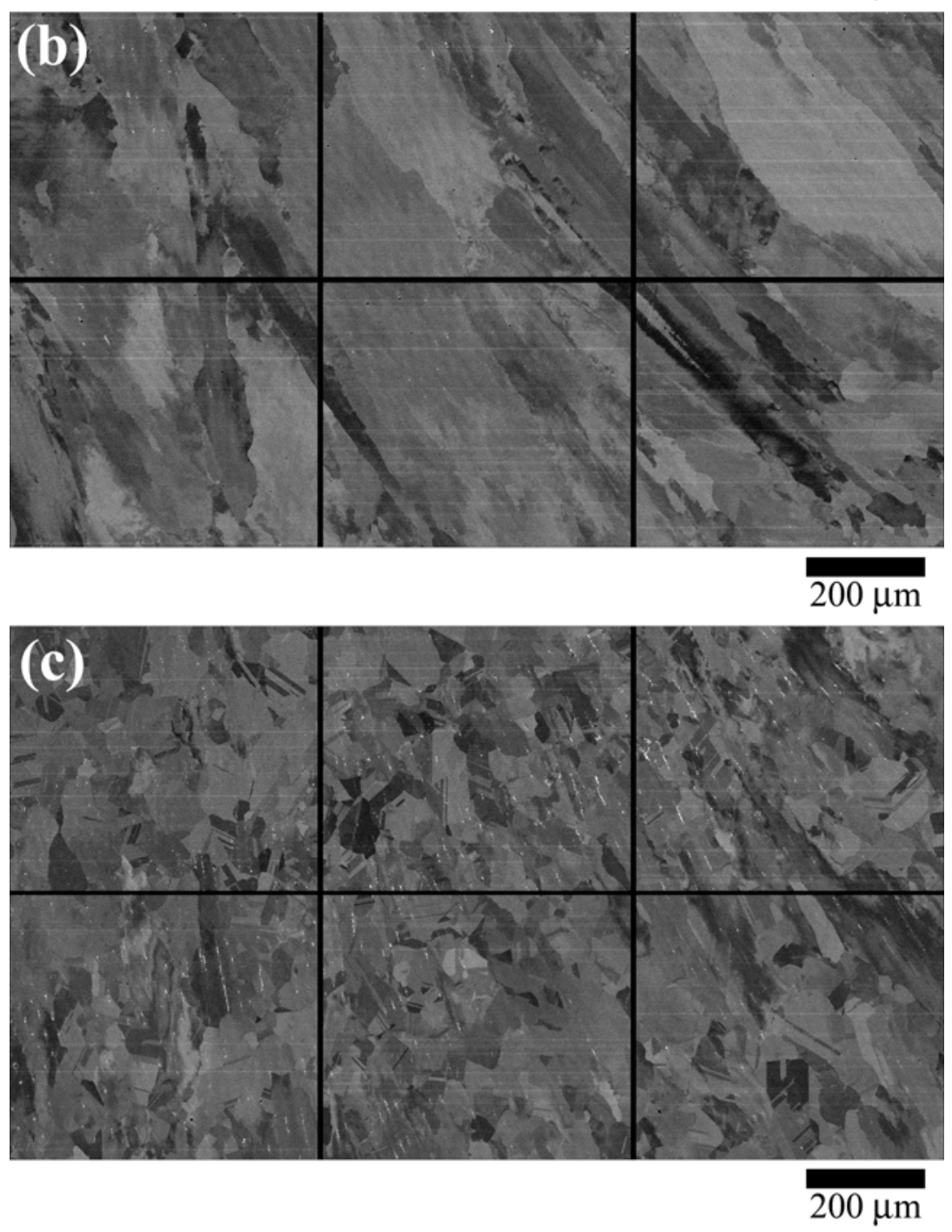

Figure 8. Sections of the collage presented in Figure 3 for the specimen annealed at $1121^{\circ} \mathrm{C}$ for 20 minutes showing (a) recrystallized grains in regions with no TCP phases present, (b) no recrystallized grains in regions with no TCP phases are present, and (c) recrystallized grains in regions with many TCP phases present. TCP phases appear white. 

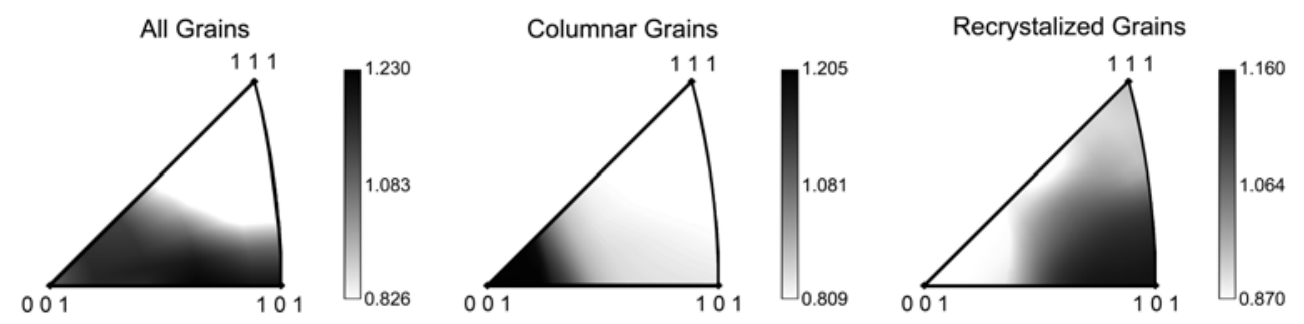

Figure 9. Inverse Pole Figure plots of the crystallographic plane normals parallel to the heat flow direction during solidification for the specimens annealed for 20 minutes at $1121^{\circ} \mathrm{C}$. The preferred plane normals are plotted for both the (original) columnar dendrites as well as the recrystallized grains. 


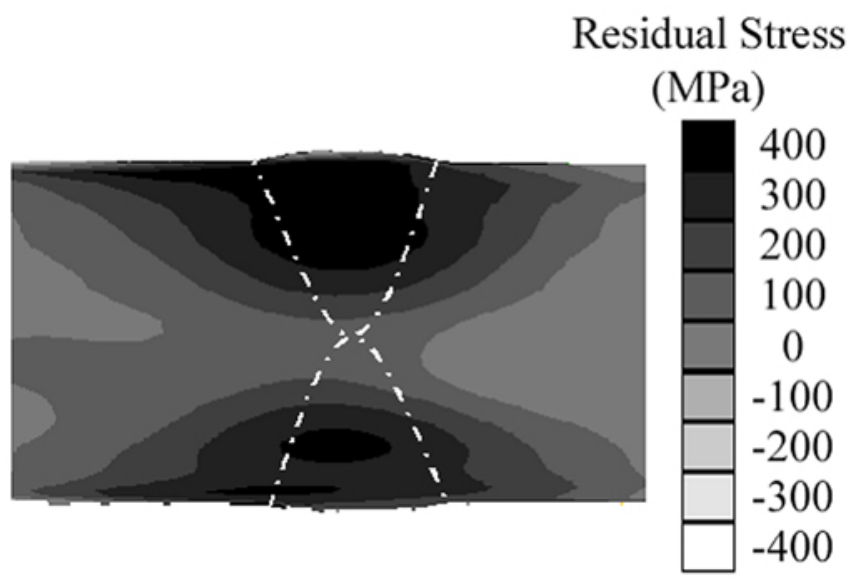

Figure 10. Stress distribution measured in Alloy-22 double-U welds. Dotted lines schematically represent the groove shape of the fusion zone (adapted with permission from ${ }^{[26]}$ ). 

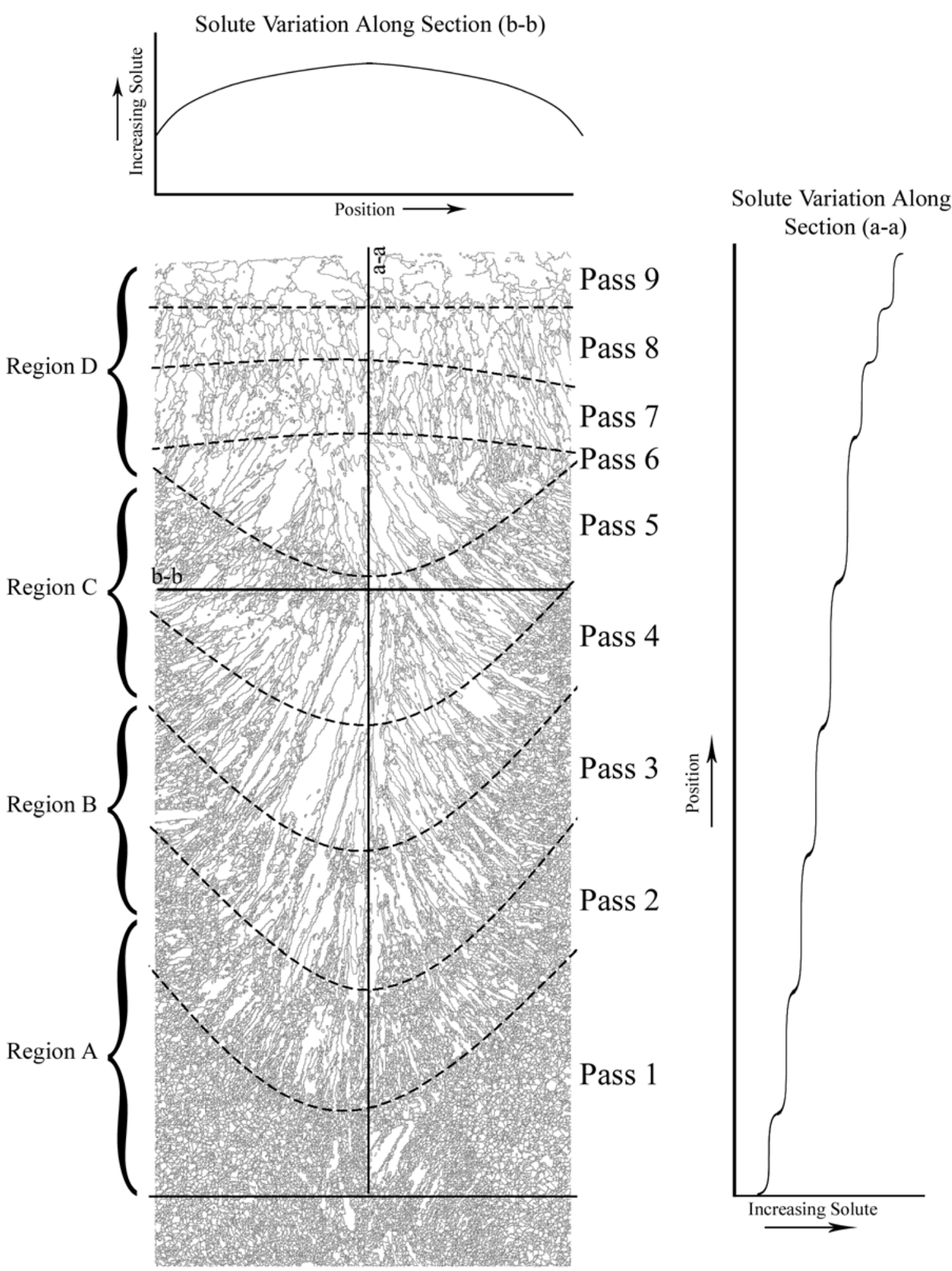

Figure 11. Grain boundary map of the specimen annealed at $1121^{\circ} \mathrm{C}$ for 20 minutes, showing locations of weld passes, and defining regions $A$ through $D$ as mentioned in the text. The proposed solute content across section (a-a) is schematically drawn on the right hand side of the figure, while that across section (b-b) is schematically drawn at the top of the figure. 
Table I. Base and Filler Metal Compositions (Weight Percent)

\begin{tabular}{|l|ccc|c|c|c|c|c|c|c|c|c|c|c|}
\hline Element & $\mathrm{Ni}$ & $\mathrm{Cr}$ & $\mathrm{Mo}$ & $\mathrm{W}$ & $\mathrm{Fe}$ & $\mathrm{Mn}$ & $\mathrm{Cu}$ & $\mathrm{Si}$ & $\mathrm{V}$ & $\mathrm{Co}$ & $\mathrm{C}$ & $\mathrm{P}$ & $\mathrm{S}$ & Others \\
\hline Base Metal Plate & 55.29 & 21.23 & 13.37 & 2.93 & 3.65 & 0.23 & 0.06 & 0.03 & 0.14 & 1.7 & 0.003 & 0.009 & 0.003 & 1.355 \\
\hline $\begin{array}{l}\text { Weld Filler } \\
\text { Metal }\end{array}$ & 59.31 & 20.44 & 14.16 & 3.07 & 2.20 & 0.21 & 0.15 & 0.07 & 0.05 & 0.03 & 0.005 & $<0.001$ & 0.001 & 0.303 \\
\hline
\end{tabular}

Table II. TCP Phase Volume Fractions and Recrystallization Behavior of Solution Annealed Alloy 22 Welds

\begin{tabular}{|c|c|c|c|c|}
\hline $\begin{array}{c}\text { Specimen } \\
\text { Number }\end{array}$ & $\begin{array}{l}\text { Annealing } \\
\text { Temperature }\end{array}$ & $\begin{array}{l}\text { Annealing } \\
\text { Duration }\end{array}$ & $\begin{array}{c}\text { Volume } \\
\text { Fraction (\%) }\end{array}$ & Recrystallization Behavior \\
\hline 1 & None & None & $0.11 \pm 0.09$ & N/A \\
\hline 2 & $1075^{\circ} \mathrm{C}$ & 20 minutes & $0.53 \pm 0.42$ & Small amount near weld toe \\
\hline 3 & $1075^{\circ} \mathrm{C}$ & 24 hours & 0 & $\begin{array}{c}\text { Banding at weld pass interfaces; grain growth } \\
\text { at root pass region }\end{array}$ \\
\hline 4 & $1075^{\circ} \mathrm{C}$ & 72 hours & 0 & $\begin{array}{c}\text { Grain coarsening near weld toe; } \\
\text { recrystallization throughout weld, except near } \\
\text { weld top }\end{array}$ \\
\hline 5 & $1075^{\circ} \mathrm{C}$ & 168 hours & 0 & $\begin{array}{l}\text { Fully recrystallized; abnormal grain growth in } \\
\text { root pass region and near fusion zone } \\
\text { boundary }\end{array}$ \\
\hline 6 & $1121^{\circ} \mathrm{C}$ & 20 minutes & $0.24 \pm 0.15$ & $\begin{array}{c}\text { Recrystallization at root pass region and } \\
\text { banding at weld pass interfaces }\end{array}$ \\
\hline 7 & $1121^{\circ} \mathrm{C}$ & 24 hours & 0 & $\begin{array}{l}\text { Fully recrystallized; large grains at root pass } \\
\text { region and near base metal }\end{array}$ \\
\hline 8 & $1121^{\circ} \mathrm{C}$ & 72 hours & 0 & $\begin{array}{l}\text { Grain growth in fusion zone; abnormal grain } \\
\text { growth near fusion zone boundary }\end{array}$ \\
\hline 9 & $1121^{\circ} \mathrm{C}$ & 168 hours & 0 & $\begin{array}{l}\text { Grain coarsening in fusion zone; abnormal } \\
\text { grain growth near fusion zone boundary }\end{array}$ \\
\hline 10 & $1200^{\circ} \mathrm{C}$ & 20 minutes & 0 & $\begin{array}{c}\text { Fully recrystallized; homogeneous grain sizes } \\
\text { observed throughout }\end{array}$ \\
\hline 11 & $1200^{\circ} \mathrm{C}$ & 24 hours & 0 & $\begin{array}{l}\text { Grain growth in fusion zone; abnormal grain } \\
\text { growth near fusion zone boundary }\end{array}$ \\
\hline 12 & $1200^{\circ} \mathrm{C}$ & 72 hours & 0 & Coarsened grains throughout \\
\hline 13 & $1200^{\circ} \mathrm{C}$ & 168 hours & 0 & Coarsened grains throughout \\
\hline 14 & $1300^{\circ} \mathrm{C}$ & 20 minutes & 0 & Abnormal grain growth in fusion zone \\
\hline 15 & $1300^{\circ} \mathrm{C}$ & 24 hours & 0 & Coarsened grains throughout \\
\hline 16 & $1300^{\circ} \mathrm{C}$ & 72 hours & 0 & Coarsened grains throughout \\
\hline 17 & $1300^{\circ} \mathrm{C}$ & 168 hours & 0 & Coarsened grains throughout \\
\hline
\end{tabular}

